\title{
openheart Multianalysis with optical coherence tomography and vasomotion in everolimus-eluting stents and everolimus-eluting biovascular scaffolds: the MOVES trial
}

Diego A Arroyo, Sara Schukraft, Zacharenia Kallinikou, Jean-Christophe Stauffer, Gérard Baeriswyl, Jean-Jacques Goy, Mario Togni, Stéphane Cook, Serban Puricel

To cite: Arroyo DA, Schukraft S, Kallinikou Z, et al. Multianalysis with optical coherence tomography and vasomotion in everolimus-eluting stents and everolimus-eluting biovascular scaffolds: the MOVES trial. Open Heart 2018;5:e000624.

doi:10.1136/

openhrt-2017-000624

DAA and SS contributed equally, $\mathrm{SC}$ and SP contributed equally.

DA and SS are co first authors SP and SC are co senior authors

Received 2 March 2017

Revised 24 November 2017

Accepted 27 November 2017

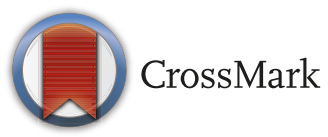

Department of Cardiology, University and Hospital Fribourg, Fribourg, Switzerland

Correspondence to Dr Serban Puricel; serbanpuricel@icloud.com

\section{ABSTRACT}

Aims To compare endothelium-dependent vasomotor function and vascular healing 15 months after implantation of two new-generation drug-eluting stents and biovascular scaffolds (BVS).

Methods and results A total of 28 patients previously treated with a SYNERGY stent (bioabsorbable polymer everolimus-eluting stents (BP-EES)), a PROMUS stent (persistent polymer everolimus-eluting stents (PP$\mathrm{EES})$ ) or an ABSORB (BVS) underwent control coronary angiography, 15 months after implantation, coupled with optical coherence tomography imaging and supine bicycle exercise. Intracoronary nitroglycerin was administered after exercise testing. Coronary vasomotor response was assessed using quantitative coronary angiography at rest, during supine bicycle exercise and after nitroglycerin. The primary end point was the percent change in mean lumen diameter compared with baseline. Secondary end points were strut coverage and apposition. There were no significant differences in vasomotor response between the three treatment groups. Patients with PP-EES showed significant vasoconstriction of the proximal peristent segment at maximum exercise $(\mathrm{P}=0.02)$. BP-EES $(2.7 \%$, $95 \% \mathrm{Cl} 0$ to 5.5$)$ and $\mathrm{BVS}(3.2 \%, 95 \% \mathrm{Cl} 0$ to 6.7$)$ showed less uncovered struts than PP-EES $(12.1 \%, 95 \% \mathrm{Cl} 2.9$ to $21.3, \mathrm{P}=0.02$ and 0.09 , respectively). Complete strut apposition was more frequently seen with BP-EES $(99.6 \%$, $95 \% \mathrm{Cl} 99.2$ to 100$)$ than with BVS $(98.9 \%, 95 \% \mathrm{Cl} 98.2$ to $99.6, \mathrm{P}=0.04)$ or PP-EES $(95.0 \%, 95 \% \mathrm{Cl} 91.6$ to 98.5 , $\mathrm{P}=0.001$ ).

Conclusion BVS and thin strut BP-EES have a reassuring vasomotion profile, suggesting minimal endothelial dysfunction 15 months after implantation.

\section{INTRODUCTION}

Drug-eluting stents (DES) are associated with a rare yet persistent risk of late and very late stent thrombosis. One of the main causes may be a delayed arterial healing due to the chronic inflammation from the persistent polymer. Uncovered struts, fibrin deposition and incomplete stent apposition are all

\section{Key questions}

What is already known about this subject?

- Persistent polymer everolimus-eluting stents (PP-EES) have been associated with paradoxical vasoconstriction around stent edges during exercise. The response to exercise in bioabsorbable polymer everolimus-eluting stents (BP-EES) has not yet been studied. Bioabsorbable vascular scaffolds (BVS) are believed to restore physiological vasomotion after absorption. However, randomised controlled trials failed to show fully restored vasomotion for BVS compared with to EES.

What does this study add?

- This study shows a reassuring vasomotion profile in two new-generation drug-eluting stents. This is the first study to assess vasomotion during physical stress testing in patients treated with BP-EES.

How might this impact on clinical practice?

- Preserved coronary endothelial function in bioabsorbable polymer devices could positively impact long-term angiographic and clinical outcomes.

associated with delayed healing at histopathology. ${ }^{1}$ Autopsy and intravascular imaging studies also demonstrate uncovered struts and incomplete stent apposition to be more common in patients suffering from stent thrombosis with metallic DES. ${ }^{2}{ }^{3}$ Another way of assessing delayed arterial healing is by testing the vasomotor response of the stented segment; healthy coronaries respond to testing, whether exercise-induced or drug-induced, by vasodilation. Stented segments with first-generation, second-generation and even third-generation DES, however, appear to lose this aptitude and display paradoxical vasoconstriction in response to exercise. ${ }^{4-6}$ 
Newer DES with bioabsorbable polymers and even platforms have been developed with the aim of reducing these drawbacks whether the putative advantage of polymer and/or platform absorption produces the desired effect, namely that of restoration of quasi-physiological endothelial function after percutaneous coronary intervention, has yet to be demonstrated. The randomised controlled ABSORB II trial failed to show a superior vasomotion profile with the use of biovascular scaffolds (BVS) compared with persistent polymer everolimus-eluting stents (PP-EES) at 3 years after injection of intracoronary nitrate. ${ }^{7}$

We sought to compare arterial healing by intravascular imaging using optical coherence tomography (OCT) and the assessment of vasomotor function between patients treated with everolimus-eluting PP-DES, thin strut everolimus-eluting BP-DES and everolimus-eluting BVS.

\section{METHODS}

\section{Trial design and participants}

This was a single-centre, non-randomised trial with an allocation ratio of 1:1:1 conducted at the University and Hospital Fribourg, Switzerland.

Patient enrolment started in July 2014 till February 2015. All patients treated with one of the studied devices for de novo coronary artery disease 12-16 months prior to the study period were eligible. Additional criteria included the ability to perform supine bicycle exercise as well as the willingness and ability to provide written informed consent. Patients unable to perform supine bicycle exercise, unwilling or unable to provide written informed consent, with any relative or absolute contraindications to undergo coronary angiography and/or known hypersensitivity to drugs administered before, during or after catheterisation, patients presenting with binary restenosis, as well as patients with stents other than the study stents on target lesions or arteries were excluded.

The patients were contacted by phone by one of the principal investigators in chronological order of their stent implantation to assess their willingness to partake in the study. Interventions were scheduled if patients gave their oral agreement by phone. Patients were enrolled at the date of the study intervention after providing written informed consent.

\section{Studied devices}

The Absorb BVS (V. 1; Abbott Laboratories, Abbott Park, Illinois, USA) has a poly-DL-lactide coating-releasing everolimus. The scaffold body is semicrystalline poly-Llactide and presents with a strut thickness of $150 \mu \mathrm{m}$. Its degradation occurs via hydrolysis, and it is completely bioabsorbed within 3-4 years via the Krebs cycle.

The SYNERGY stent (Boston Scientific Corporation, Marlborough, Massachusetts, USA) is made of a platinum chromium platform, which has a thickness of $74 \mu \mathrm{m}$. It is coated on its abluminal side with a bioabsorbable polymer consisting of amorphous poly-lactide-coglycide (PGLA)-eluting everolimus. Drug and polymer are absorbed within 4 months after device implantation.

The Promus Element stent (Boston Scientific Corporation) consists of a platinum chromium alloy with a strut thickness of $81 \mu \mathrm{m}$. Its durable, biocompatible acrylic polymer and fluorinated copolymer elutes everolimus $\left(100 \mathrm{mg} / \mathrm{cm}^{2}\right)$.

\section{Study end points}

The primary end point was vasomotor response of the stented segment and the proximal and distal peristent segments at maximum exercise defined as per cent change in mean lumen diameter from baseline. Secondary end points were strut coverage and apposition as assessed by OCT imaging.

\section{Study interventions}

Endothelium-dependent and independent function

Vasoactive drugs were withheld 48 hours prior to angiography. Vasomotor function was assessed using supine bicycle exercise testing. Patients underwent coronary catheterisation with a 5-French guidewire using the radial artery access. First, standard coronary angiography was performed in order to exclude binary restenosis of the target lesion or significant progression of coronary artery disease prior to exercise testing. In the absence of significant restenosis, consent for the procedure was confirmed and a bolus of 5000 units of heparin was administered intravenously. Prespecified criteria for the interruption of supine bicycle comprised the occurrence of angina, significant ST-elevations, cerebral symptoms, evidence for peripheral hypoperfusion such as pallor or cyanosis or sustained arrhythmias such as ventricular tachycardia.

Vasomotion testing was initiated with a $2 \mathrm{~min}$ supine bicycle exercise interval at a workload of $50 \mathrm{~W}$ with the catheter remaining intravascular. After $1 \mathrm{~min}$ of rest, exercise was performed for $2 \mathrm{~min}$ at a workload of $100 \mathrm{~W}$, followed by the intracoronary administration of $300 \mu \mathrm{m}$ of nitroglycerin. Digital angiograms of the target lesion perpendicular to the studied device in order to minimise foreshortening, heart rate (HR), systolic blood pressure (SBP), diastolic blood pressure (DBP) and mean blood pressure (MBP) were collected at rest and after each interval (50 W, $100 \mathrm{~W}$, nitroglycerin).

\section{Optical coherence tomography}

OCT was performed after supine bicycle exercise testing using a commercially available system (C7-XR, Dragon Fly, LightLab, St. Jude Medical, St. Paul, Minnesota, USA) according to manufacturer guidelines using the Duo OCT Imaging Catheter with ' $54 \mathrm{~mm}$ high resolution mode' pullback, the non-occlusive flushing technique and a pullback speed of $25 \mathrm{~mm} / \mathrm{s}$. OCT pullbacks were assessed offline using a proprietary software.

Lesions were analysed at cross-sectional level with an interval of $1 \mathrm{~mm}$ and assessed for strut coverage, malapposition and protrusion by a single analyst (SS) blinded to 
patient and lesion presentation. All frames were reviewed by a second analyst (SP) with final decision based on consensus. Pullbacks were excluded in cases where $>30 \%$ of the total stent length was not analysable. The lumen contour was drawn by semiautomated detection software, following the endoluminal contour of the neointima with manual correction wherever required. Metallic DES and BVS have different imaging properties when analysed by OCT; the main measurements (strut core area, strut area, lumen area, scaffold area, incomplete scaffold apposition area and neointimal area) require different analysis rules. OCT analysis was performed prior to the publication of the standard comparative analysis methods by Nakatani and colleagues ${ }^{8}$ and presents with the following methodology: strut malapposition was defined as a distance $\geq 160 \mu \mathrm{m}$ for BVS (strut thickness $150 \mu \mathrm{m}$ ), $\geq 84 \mu \mathrm{m}$ for BP-EES (strut thickness $74 \mu \mathrm{m}$ ) and $\geq 91 \mu \mathrm{m}$ for PP-EES (strut thickness $81 \mu \mathrm{m}$ ) based on the consensus derived from the strut thickness plus the minimal axial resolution of OCT. Strut protrusion was defined as strut extension into the lumen for $>160 \mu \mathrm{m}$ but with no obvious separation from the vessel wall. Cross-sectional areas of lumen, stent and neointima were measured at intervals of $1 \mathrm{~mm}$ in the stented segment, as well as the luminal areas of the proximal and distal non-stented reference segments. Neointima area was defined as stent area minus lumen area. Representative images of OCT analyses for both BVS and DES are provided in one of our previous publications. ${ }^{9}$ Neointima area was defined as stent area minus lumen area. Struts were classified into either apposed, protruding or malapposed.

\section{Quantitative coronary angiography}

Coronary angiography was performed on a digital X-ray system (Philips DCI) at 12.5 frames/s. Multiple monoplane projections were acquired in all patients. Rotation and angulation were adapted to minimise foreshortening of the target vessel. Quantitative evaluation was carried out in monoplane projections. Coronary vasomotor response was assessed using quantitative coronary angiography at rest, during supine bicycle exercise at 50 and 100 $\mathrm{W}$ and after nitroglycerine (NTG) administration. Data analysis was performed with the ACE package on Philips DCI with a documented accuracy of $\leq 0.01 \mathrm{~mm}$, precision of $\leq 0.1 \mathrm{~mm}$, intraobserver variability of $0.11 \mathrm{~mm}$ and interobserver variability of $0.10 \mathrm{~mm}$. The contrast-filled tip of the diagnostic catheter was used for calibration. All measurements were performed by an independent observer, blinded to the study protocol. Per cent changes were calculated in all patients with the baseline angiogram used as reference. The stented segment, adjacent segments and a reference vessel segment not related to the stented lesion were assessed. To optimise measurement accuracy, three measurements were carried out and averaged for each segment.

\section{STATISTICAL ANALYSIS}

Statistical analysis was performed using STATA MP.13. Baseline patient and angiographic characteristics, exercise haemodynamics, quantitative coronary angiography and OCT measurements were compared between patients receiving BVS, BP-EES and PP-EES.

Categorical variables are reported as counts and percentages, continuous variables are reported as means and SD or as medians with $25 \%-75 \%$ IQRs according to their distribution. Distribution of continuous variables was assessed by visual inspection of QQ-plots and the Shapiro-Wilk test.

For between-group comparison of baseline and procedural characteristics, exercise haemodynamics and vasomotion we used the $\chi^{2}$ or Fisher's exact test for categorical variables, one-way analysis of variance for continuous variables with a normal distribution and the Kruskal-Wallis test for continuous variables that did not show a normal distribution according to Gauss. Within-group comparison of vasomotor function was assessed by a paired t-test for normally distributed variables and by a Wilcoxon signed-rank sum test for non-normally distributed values.

A multilevel hierarchical linear regression including random effects at patient and lesion level was used to estimate the differences in OCT end points between groups. Estimates are provided with $95 \%$ CIs. Correlation of OCT measurements with vasomotion was analysed using Spearman's rank correlation.

No sample size calculation was performed. At the time of study initiation and to our knowledge, no data on vasomotion at 15 months were available for BP-EES and vasomotion in BVS had only been assessed for the ABSORB 1.0 using distinct methods (injection of acetylcholine and methylergometrine maleate).

\section{RESULTS}

Baseline patient, angiographic and procedural characteristics A total of 28 patients were included (BVS: $n=8$; BP-EES: $\mathrm{n}=10$; PP-EES: $\mathrm{n}=10$ ) at a mean of $15 \pm 2$ months after index procedure. Baseline patient, angiographic and procedural characteristics are outlined in table 1 . There were no significant differences with regard to age $(\mathrm{P}=0.78)$ or gender $(\mathrm{P}=1.00)$ between the three groups. There was a trend towards a higher proportion of patients suffering from diabetes in patients with PP-EES $(\mathrm{n}=4,40 \%)$ compared with patients with BVS $(\mathrm{n}=1,13 \%, \mathrm{P}=0.05)$ or BP-EES $(\mathrm{n}=0,0 \%, \mathrm{P}=0.05)$. Left ventricular ejection fraction was preserved and similar for all groups $(\mathrm{P}=0.62)$. Patients treated with either BP- $(\mathrm{n}=8,80 \%)$ or PP-EES $(\mathrm{n}=6,60 \%)$ presented more frequently with complex lesions than patients treated with BVS $(n=3,38 \%$, $\mathrm{P}=0.25)$ even though this was not statistically significant. After index procedure, the residual diameter stenosis was higher for BP-EES-treated patients $(9 \% \pm 7 \%)$ than for PP-EES $(4 \% \pm 3 \%)$ or BVS $(4 \% \pm 3 \%)$-treated patients $(\mathrm{P}=0.02)$. 
Table 1 Baseline patient, angiographic and procedural characteristics

\begin{tabular}{|c|c|c|c|c|}
\hline & BVS $(n=8)$ & BP-EES $(n=10)$ & PP-EES $(n=10)$ & $P$ value \\
\hline \multicolumn{5}{|l|}{ Anthropometric } \\
\hline Age (years), mean $\pm S D$ & $65 \pm 7$ & $60 \pm 8$ & $58 \pm 8$ & 0.78 \\
\hline Male, n (\%) & $6(75)$ & $7(70)$ & $8(80)$ & 1.00 \\
\hline Weight (kg) & $80 \pm 17$ & $80 \pm 6$ & $80 \pm 12$ & 0.96 \\
\hline Height $(m)$, mean $\pm S D$ & $1.74 \pm 0.08$ & $1.70 \pm 0.11$ & $1.71 \pm 0.09$ & 0.70 \\
\hline $\mathrm{BMI}\left(\mathrm{kg} / \mathrm{m}^{2}\right)$, mean $\pm \mathrm{SD}$ & $26 \pm 4$ & $28 \pm 3$ & $27 \pm 5$ & 0.69 \\
\hline \multicolumn{5}{|l|}{ Risk factors } \\
\hline Hypertension, n (\%) & $6(75)$ & $3(30)$ & $3(30)$ & 0.13 \\
\hline Smoking, n (\%) & $5(63)$ & $5(50)$ & $4(40)$ & 0.74 \\
\hline Diabetes, n (\%) & $1(13)$ & $0(0)$ & $4(40)$ & 0.05 \\
\hline Dyslipidaemia, $n(\%)$ & $4(50)$ & $3(30)$ & $1(10)$ & 0.20 \\
\hline Family history, n (\%) & $2(25)$ & $1(10)$ & $1(10)$ & 0.65 \\
\hline \multicolumn{5}{|l|}{ Presentation at index procedure } \\
\hline Stable angina, $\mathrm{n}(\%)$ & $5(63)$ & $3(30)$ & $1(10)$ & 0.08 \\
\hline Acute coronary syndrome, $\mathrm{n}(\%)$ & $2(25)$ & $7(70)$ & $8(80)$ & 0.09 \\
\hline $\operatorname{LVEF}(\%)$, mean $\pm S D$ & $62 \pm 10$ & $61 \pm 12$ & $56 \pm 11$ & 0.62 \\
\hline Multivessel disease, $\mathrm{n}(\%)$ & $2(25)$ & $4(40)$ & $4(40)$ & 0.79 \\
\hline \multicolumn{5}{|l|}{ Angiographic characteristics of target lesion } \\
\hline \multicolumn{5}{|l|}{ Stented vessel } \\
\hline LM, n (\%) & $0(0)$ & $0(0)$ & $0(0)$ & \\
\hline LCX, n (\%) & $1(13)$ & $5(5)$ & $3(30)$ & 0.27 \\
\hline LAD, n (\%) & $6(75)$ & $2(2)$ & $4(40)$ & 0.07 \\
\hline RCA, n (\%) & $1(13)$ & $3(30)$ & $3(30)$ & 0.75 \\
\hline Per cent stenosis, mean \pm SD & $72 \pm 15$ & $83 \pm 17$ & $75 \pm 17$ & 0.92 \\
\hline $\operatorname{MLD}(\mathrm{mm})$, mean $\pm \mathrm{SD}$ & $0.86 \pm 0.47$ & $0.39 \pm 38$ & $0.79 \pm 0.60$ & 0.43 \\
\hline $\mathrm{RVD}(\mathrm{mm})$, mean $\pm \mathrm{SD}$ & $3.05 \pm 0.43$ & $2.64 \pm 0.50$ & $3.01 \pm 0.49$ & 0.92 \\
\hline Lesion length $(\mathrm{mm})$, mean $\pm \mathrm{SD}$ & $11 \pm 5$ & $15 \pm 9$ & $14 \pm 6$ & 0.29 \\
\hline Lesion complexity & & & & 0.25 \\
\hline Simple A/B1, n (\%) & $5(63)$ & $2(20)$ & $4(40)$ & \\
\hline Complex B2/C, n (\%) & $3(38)$ & $8(80)$ & $6(60)$ & \\
\hline \multicolumn{5}{|l|}{ Procedural characteristics of target lesion } \\
\hline Predilation, n (\%) & $8(100)$ & $8(80)$ & $8(80)$ & 0.51 \\
\hline Stents implanted in target lesion, $\mathrm{n}$, median (IQR) & $1(1-1)$ & $1(1-2)$ & $1(1-1)$ & 0.47 \\
\hline Stent length $(\mathrm{mm})$, mean $\pm \mathrm{SD}$ & $18(18-18)$ & $16(16-20)$ & $18(18-24)$ & 0.27 \\
\hline Stent diameter $(\mathrm{mm})$, mean \pm SD & $3.25(3.00-3.50)$ & $3.00(3.00-3.00)$ & $3.00(3.00-3.50)$ & 0.54 \\
\hline Max. inflation pressure (atm), median (IQR) & $14(13-14)$ & $14(14-16)$ & $14(14-16)$ & 0.43 \\
\hline Stent overlap, $\mathrm{n}(\%)$ & $1(13)$ & $3(30)$ & $1(10)$ & 0.58 \\
\hline Postdilation, n (\%) & $3(38)$ & $5(50)$ & $7(70)$ & 0.42 \\
\hline \multicolumn{5}{|l|}{ Postprocedural } \\
\hline MLD in stent $(\mathrm{mm})$, mean \pm SD & $2.70 \pm 0.24$ & $2.59 \pm 0.38$ & $2.88 \pm 0.51$ & 0.50 \\
\hline Per cent stenosis, mean $\pm S D$ & $4 \pm 3$ & $9 \pm 7$ & $4 \pm 3$ & 0.02 \\
\hline
\end{tabular}

BMI, body mass index; BP-EES, bioabsorbable polymer everolimus-eluting stents; BVS, biovascular scaffolds; IQR, IQR (25\%$75 \%$ percentile); LAD, left anterior descending artery; LCX, left circumflex artery; LM, left main artery; LVEF, left ventricular ejection fraction; MLD, mean lumen diameter; PP-EES, persistent polymer everolimus -eluting stents; RCA, right coronary artery; RVD, referencevessel diameter. 


\begin{tabular}{|c|c|c|c|c|}
\hline & BVS $(n=8)$ & $\begin{array}{l}\text { BP-EES } \\
(n=10)\end{array}$ & $\begin{array}{l}\text { PP-EES } \\
(n=10)\end{array}$ & $P$ value \\
\hline \multicolumn{5}{|l|}{ Baseline } \\
\hline $\begin{array}{l}\text { Heart rate } \\
(\mathrm{bpm})\end{array}$ & $68 \pm 13$ & $71 \pm 16$ & $66 \pm 6$ & 0.02 \\
\hline $\mathrm{DBP}(\mathrm{mm} \mathrm{Hg})$ & $86 \pm 18$ & $84 \pm 14$ & $81 \pm 14$ & 0.66 \\
\hline $\mathrm{SBP}(\mathrm{mm} \mathrm{Hg})$ & $155 \pm 22$ & $142 \pm 26$ & $138 \pm 28$ & 0.84 \\
\hline \multicolumn{5}{|l|}{$50 \mathrm{~W}$} \\
\hline $\begin{array}{l}\text { Heart rate } \\
(\mathrm{bpm})\end{array}$ & $96 \pm 15$ & $95 \pm 18$ & $92 \pm 12$ & 0.51 \\
\hline $\mathrm{DBP}(\mathrm{mm} \mathrm{Hg})$ & $98 \pm 24$ & $104 \pm 21$ & $92 \pm 22$ & 0.44 \\
\hline $\mathrm{SBP}(\mathrm{mm} \mathrm{Hg})$ & $156 \pm 27$ & $174 \pm 38$ & $163 \pm 31$ & 0.64 \\
\hline RPP & $15094 \pm 4023$ & $16969 \pm 5357$ & $14889 \pm 4603$ & 0.74 \\
\hline \multicolumn{5}{|l|}{$100 \mathrm{~W}$} \\
\hline $\begin{array}{l}\text { Heart rate } \\
(\mathrm{bpm})\end{array}$ & $104 \pm 24$ & $123 \pm 32$ & $99 \pm 13$ & 0.13 \\
\hline $\mathrm{DBP}(\mathrm{mm} \mathrm{Hg})$ & $94 \pm 26$ & $108 \pm 27$ & $92 \pm 30$ & 0.35 \\
\hline $\mathrm{SBP}(\mathrm{mm} \mathrm{Hg})$ & $163 \pm 31$ & $182 \pm 37$ & $171 \pm 23$ & 0.45 \\
\hline RPP & $17371 \pm 6538$ & $22142 \pm 5895$ & $16745 \pm 2679$ & 0.11 \\
\hline $\begin{array}{l}\mathrm{RPP}>20000 \\
\mathrm{n}(\%)\end{array}$ & $2(25)$ & $6(60)$ & $1(10)$ & 0.14 \\
\hline \multicolumn{5}{|l|}{ After nitroglycerin } \\
\hline $\begin{array}{l}\text { Heart rate } \\
(\mathrm{bpm})\end{array}$ & $83 \pm 10$ & $86 \pm 17$ & $73 \pm 12$ & 0.16 \\
\hline $\mathrm{DBP}(\mathrm{mm} \mathrm{Hg})$ & $84 \pm 15$ & $84 \pm 19$ & $73 \pm 17$ & 0.32 \\
\hline $\mathrm{SBP}(\mathrm{mm} \mathrm{Hg})$ & $131 \pm 23$ & $136 \pm 27$ & $118 \pm 18$ & 0.29 \\
\hline
\end{tabular}

Values are expressed as mean $\pm S D$.

BP-EES, bioabsorbable polymer everolimus-eluting stent; BVS, biovascular scaffolds; DBP, diastolic blood pressure; PP-EES, persistent polymer everolimus-eluting stent; RPP, rate pressure product in $\mathrm{mm} \mathrm{Hg}^{*}$ bpm; SBP, systolic blood pressure.

\section{Exercise haemodynamics}

Haemodynamic parameters are displayed in table 2. The proportion of patients reaching a rate pressure product of $\geq 20000 \mathrm{~mm} \mathrm{Hg} / \mathrm{min}$ was $25 \% \quad(\mathrm{n}=2)$ in BVS-treated, $60 \%(\mathrm{n}=6)$ in BP-EES-treated and $10 \%(\mathrm{n}=1)$ in PP-EEStreated patients, respectively $(\mathrm{P}=0.14)$.

\section{Quantitative coronary angiography measurements}

There were no significant differences in vasomotor response between the three treatment groups except for vasodilation of the distal peristent segment in BVS-treated patients at a workload of $50 \mathrm{~W}$. This was reflected by an increase in mean lumen diameter $(+9 \% \pm 11 \%)$ compared with BP-EES-treated $(-3 \pm 8 \%)$ or PP-EES $(-3 \% \pm 7 \%)$ treated patients $(\mathrm{P}=0.02)$ who showed vasoconstriction (table 3).

Patients treated with BVS showed significant vasodilation of the distal peristent segment at $50 \mathrm{~W}$ (mean lumen diameter: $+9 \% \pm 11 \%, \mathrm{P}=0.01)$ and after nitroglycerin administration (mean lumen diameter: $+20 \% \pm 14 \%$, $\mathrm{P}=0.01$ ). The BP-EES group did not have any significant changes in mean lumen diameter at $50 \mathrm{~W}, 100 \mathrm{~W}$ or after nitroglycerin administration. PP-EES-treated patients showed significant vasoconstriction of the proximal peristent segment at maximum exercise (mean lumen diameter: $-10 \% \pm 5 \%, \mathrm{P}=0.02)$ and significant vasodilation of proximal $(\mathrm{P}=0.03)$ and distal $(\mathrm{P}=0.01)$ peristent segments after nitroglycerin administration (figure 1 ).

\section{OCT analysis}

A total of 5059 struts were analysed: 1796 in the BVS, 1316 in the BP-EES and 1947 in the PP-EES group, respectively. Detailed information on OCT analysis is provided in table 4. PP-EES showed the highest percentage of uncovered struts $(12.1 \%, 95 \%$ CI 2.9 to 21.3). BP-EES showed significantly higher mean neointimal thickness $(117 \mu \mathrm{m}$, $95 \%$ CI 86 to 147$)$ than PP-EES $(82 \mu \mathrm{m}, 95 \%$ CI 60 to 105 , $\mathrm{P}=0.02)$. Well-apposed struts were more frequently seen with BP-EES (99.6\%, 95\% CI 99.2 to 100) than with BVS $(98.9 \%, 95 \%$ CI 98.2 to $99.6, \mathrm{P}=0.04)$ or PP-EES $(95.0 \%$, $95 \%$ CI 91.6 to $98.5, \mathrm{P}=0.001)$.

\section{Correlation between OCT and vasomotion}

There was no significant association between concomitant changes in mean lumen diameter of the proximal and distal peristent segments at maximum exercise and any of the OCT parameters. Only strut protrusion showed a significant, negative association with vasomotion of the proximal peristent segment at maximum exercise (rho: $-0.50, \mathrm{P}=0.03$ ). Other correlation coefficients are provided in table 5 .

\section{DISCUSSION}

The present vasomotion and OCT study has the following findings:

1. Unlike earlier generation DES, BVS and thin strut BP-EES do not show significant exercise-induced vasoconstriction around stent edges.

2. Arterial healing 15 months after implantation of BVS and BP-EES is excellent.

The normal endothelium is a finely tuned machinery of vasomotor tone (nitric oxide), vascular inflammation inhibition (prostaglandins), local thrombolysis and fibrinolysis (tissue plasminogen activator).$^{10}$ Unsurprisingly, the dysfunctional endothelium may lead to a thrombogenic environment and adverse clinical outcomes. Coronary vasomotion is impaired in coronary artery disease, resulting in exercise-induced vasoconstriction at the site of the stenotic lesions. ${ }^{11}$ Exercise-induced paradoxical vasoconstriction has consistently been observed around stent edges in first-generation, second-generation and third-generation DES and is believed to be a sign of endothelial dysfunction (ED). Impaired endothelial function after stent implantation has been linked to delayed arterial healing due to chronic inflammation in response to the stent itself, the bioabsorbable polymer (DES) or the cytostatic drug (DES). ${ }^{4-6} 12-14$

Our results show paradoxical vasoconstriction at the proximal stent edge and thus possible ED 16 months after implantation of a second-generation EES with persistent 
Table 3 Quantitative coronary angiography measurements

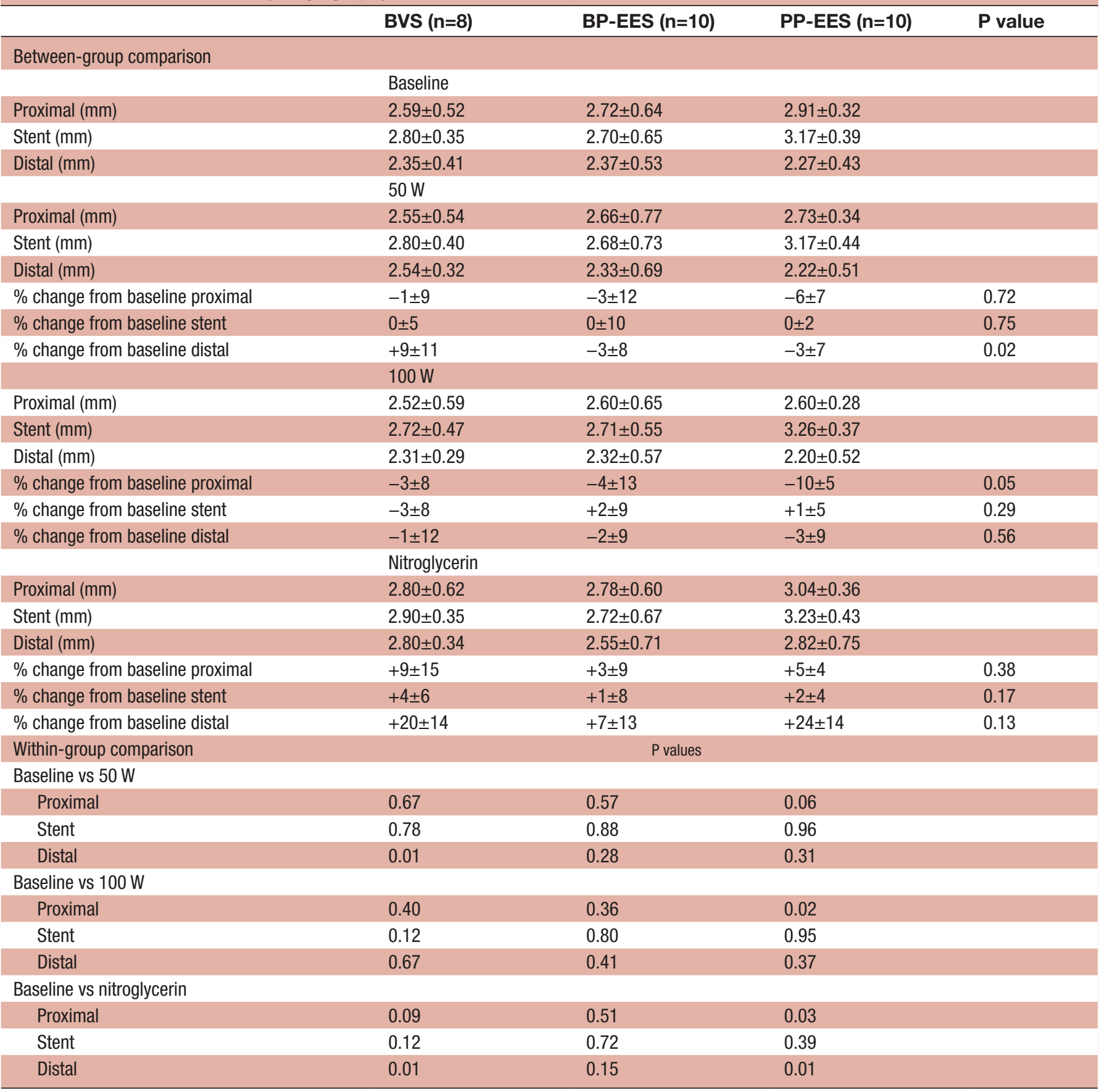

Values are expressed as mean \pm SD.

BP-EES, bioabsorbable polymer everolimus-eluting stent; BVS, biovascular scaffolds; PP-EES, persistent polymer everolimus-eluting stent.

polymer. This finding confirms previous investigations that have found paradoxical vasoconstriction around PP-EES edges at exercise or after acetylcholine administration. ${ }^{15} 16$

Impaired endothelial function after first-generation and second-generation DES implantation has been linked with a lack of strut coverage. ${ }^{17}$ However, the evidence linking a lack of strut coverage to endothelial dysfunction is somewhat conflicting. Won et al recently reported no correlation of strut coverage and vasomotion for sirolimus-eluting and biolimus-eluting stents after acetylcholine administration. ${ }^{19}$ Similarly, our study did not confirm a statistically significant relationship between strut coverage, apposition or mean neointimal thickness and vasomotion in response to supine bicycle exercise testing. Nonetheless, the OCT analysis showed an extensive lack of strut coverage and a high percentage of malapposed struts for PP-EES, which may be explained by the small sample size and thus be the result of random variation.

The SYNERGY stent is a new-generation BP-EES. Its distinctive features from earlier generation BP-DES, such as biolimus-eluting devices, include a thinner platform 
BP-EES/SYNERGYTM

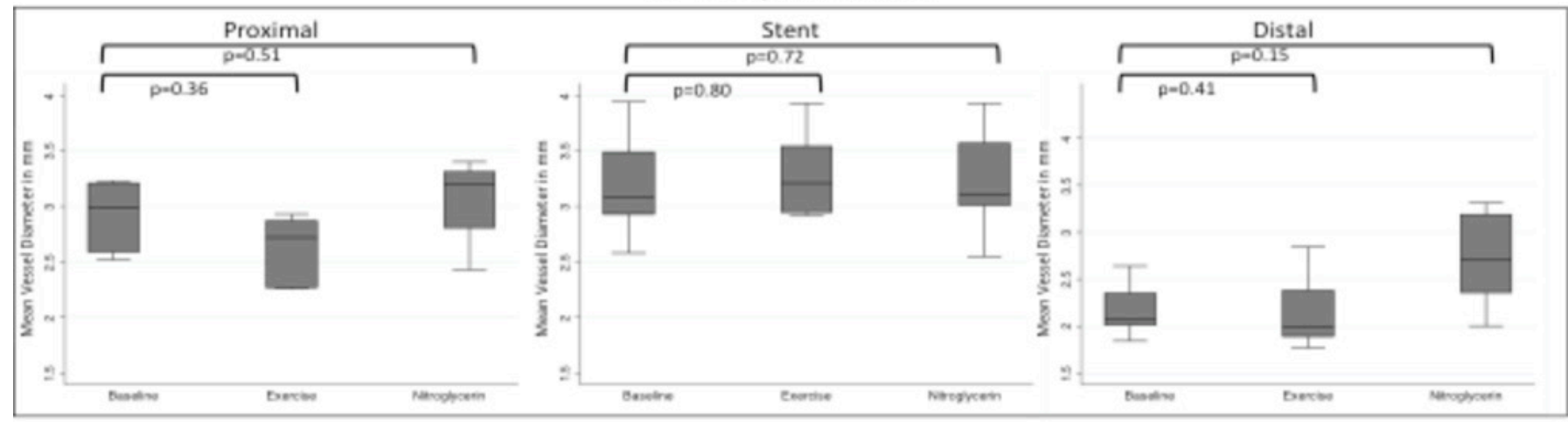

BVS/ABSORB ${ }^{m}$

P.volues are derived from within group comparisons

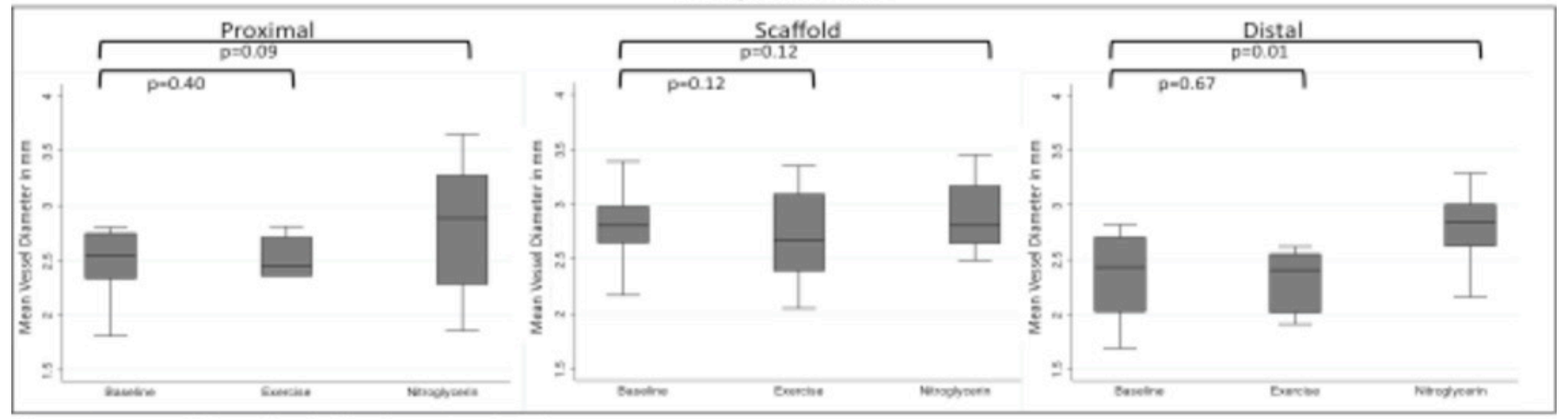

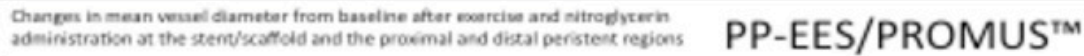
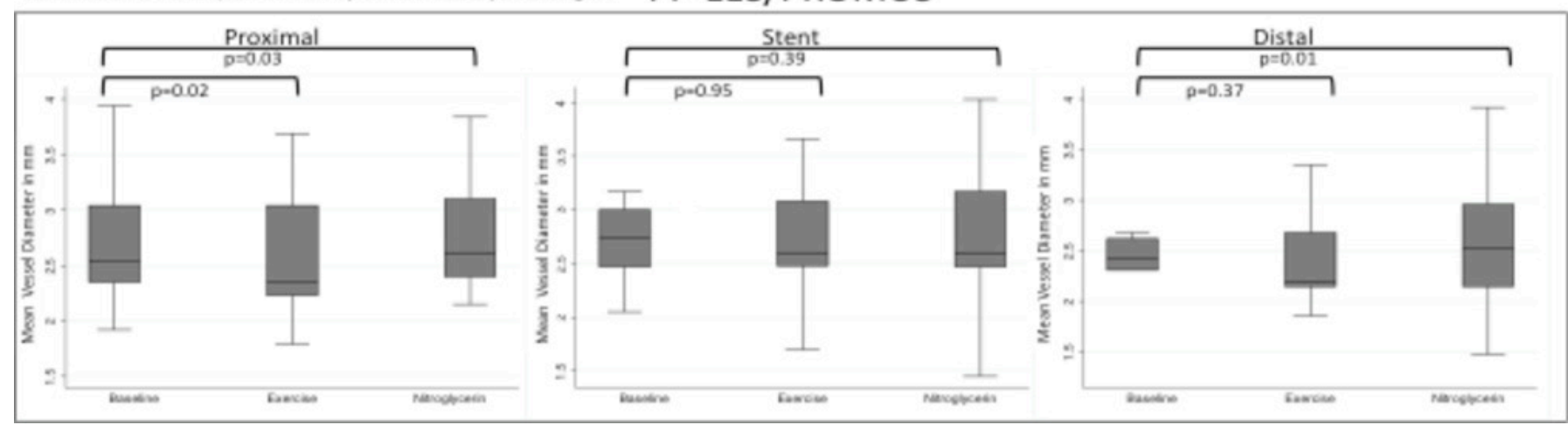

Figure 1 Vasomotion of the stent/scaffold and the persistent regions. Changes in mean lumen diameter after exercise and nitroglycerin administration according to implanted stent/scaffold at 15 months. BP-EES, bioabsorbable polymer everolimuseluting stent; BVS, biovascular scaffold; EEM, external elastic membrane; PP-EES, persistent polymer everolimus-eluting stent.

and improved drug release kinetics. Furthermore, the bioabsorbable polymer consists of PGLA instead of poly-DL-lactide (PLLA) with a quicker bioabsorption. These attributes are believed to positively impact arterial healing and to prevent chronic inflammation of the vessel wall. The present investigation found a small degree of non-significant vasoconstriction around stent edges for the BP-EES at maximum exercise. This may well be the reflection of its enhanced design that manifests itself with improved arterial healing and relatively preserved endothelial function compared with second-generation EES or earlier generation BP-DES. On the other hand, and as the administration of nitroglycerin did not induce significant vasodilation of peristent segments, this may simply imply an inadequately small sample to detect differences in mean lumen diameter.

In the long term, the benefit of preserved endothelial function could be a decreased incidence of late and very late stent thrombosis. In the EVOLVE II trial (Efficacy and safety of a novel bioabsorbable polymer-coated, everolimus-eluting coronary stent), assessing the efficacy and safety of SYNERGY compared with PROMUS reported an incidence of $0.4 \%$ of definite ST at 1 year. ${ }^{20}$ The Swedish real-world registry Swedish Coronary Angiography and Angioplasty Registry confirmed the low incidence of ST and reported rates of $0.25 \%$ at 1 year. ${ }^{21}$

To our knowledge, only one study has to date provided OCT data in 40 patients 3 and 6 months post SYNERGY stent implantation. ${ }^{22}$ In this two-centre non-randomised 


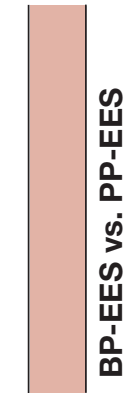

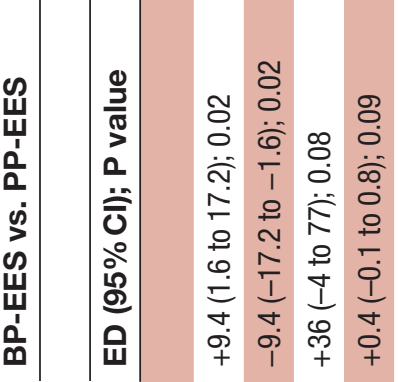

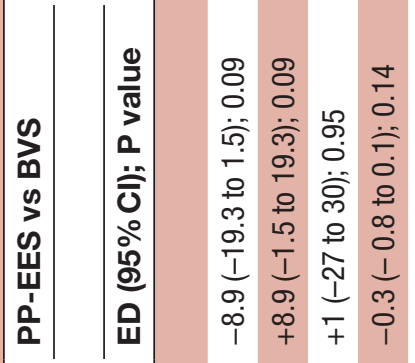

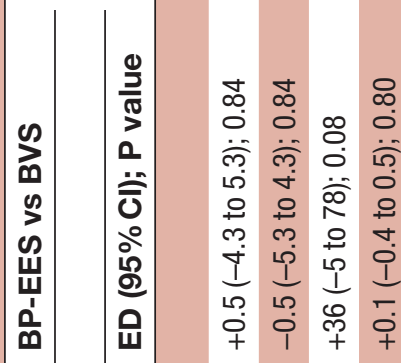

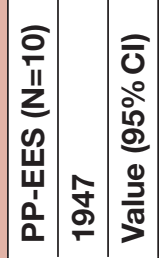

ल.

बे ल

1 $\begin{gathered}0 \\ 1\end{gathered}$

일

ำ

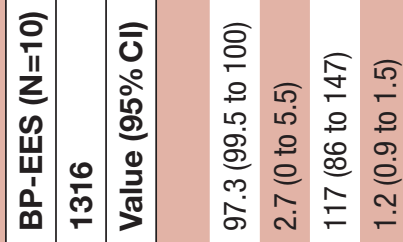

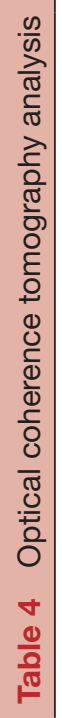

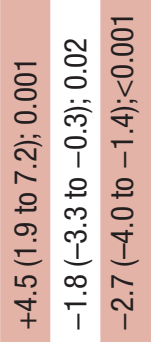

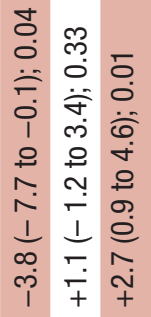

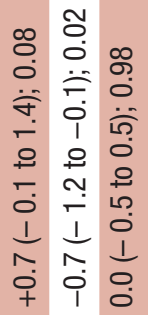

\section{$\frac{\mathscr{8}}{\frac{2}{2}}$}

a 욷 8 8

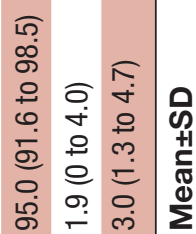

8

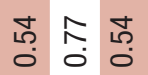

인

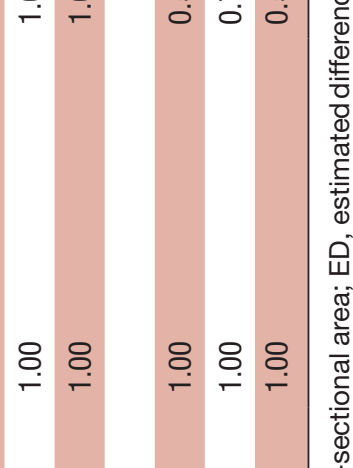

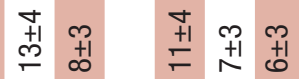

웅

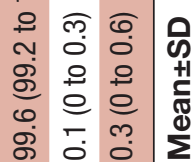

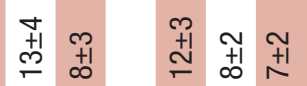

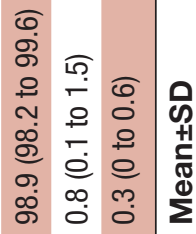

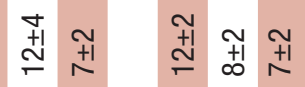

$\frac{0}{8}$

I

$\cong$

$\underset{\vec{F}}{\stackrel{\vec{O}}{+}}$

흘

$\stackrel{8}{2}$

क

$\vec{\ominus}$

$\omega$

음

골

옹

옹

$+$

인

ڤ్

옹

망

方

$\frac{0}{\mathbb{Q}}$

$\overrightarrow{\overrightarrow{0}}$

쿻

흥

궁

$\stackrel{2}{\stackrel{2}{2}}$

을.

올

옹

공.

N

竞

웡잉

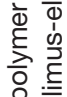

응

웡

홓

क्षे

음 움

㟧 
Table 5 Correlation of OCT findings with vasomotion

Proximal peristent Distal peristent segment segment

\begin{tabular}{lcllll}
\hline & Rho & P value & & Rho & P value \\
\hline Strut coverage & 0.19 & 0.43 & & -0.25 & 0.29 \\
$\begin{array}{l}\text { Thickness of strut } \\
\text { coverage }\end{array}$ & 0.24 & 0.32 & & -0.40 & 0.09 \\
$\begin{array}{l}\text { Strut malapposition } \\
\text { Strut protrusion }\end{array}$ & -0.15 & 0.55 & & 0.33 & 0.17 \\
\hline
\end{tabular}

Spanish study, the proportion of uncovered but apposed struts was $2.5 \%$ and $1.9 \%$ in the 3-month and 6-month group $(\mathrm{P}=0.03)$ and the proportion of uncovered and malapposed struts was $3 \%$ and $1.8 \%$, respectively $(\mathrm{P}<0.001)$. An experimental study in atherosclerotic swines previously showed a very low degree of parastrut inflammation 30 days after implantation of the device. ${ }^{23}$ The SYNERGY stent showed excellent strut coverage and apposition in the present trial, which may ultimately be at the heart of its low stent thrombosis rate.

The ABSORB BVS has specifically been designed to address the issue of delayed arterial healing, late device failure and to restore physiological vasomotion. So far, the device has been shown non-inferior to PP-EES and bioabsorbable polymer biolimus-eluting stents for angiographic end points of late lumen loss at 9 months as well as for target lesion failure at 1 year. ${ }^{24}{ }^{25}$ Three recently published meta-analyses showed a clear trend towards increased rates of myocardial infarction and stent thrombosis with BVS compared with PP-EES at 1-year follow-up. ${ }^{26-28}$ ABOSRB II was designed to show the BVS superiority over PP-EES at 3 years for vasomotion of the stented segment after nitroglycerin administration (mean lumen diameter pre and post nitrate) ${ }^{29}$ ABSORB II failed to show superiority of the BVS over PP-EES for vasomotion after injection of coronary nitrate 3 years after implantation. ${ }^{7}$ In our study, the BVS failed to show significant vasodilation of the stented segment at maximum exercise or after intracoronary nitroglycerin administration. Serruys and colleagues reported non-significant vasodilation after acetylcholine injection in nine patients, 2years after device implantation. ${ }^{30}$ Interestingly, after intracoronary nitroglycerin injection significant vasodilatation of the stented segment as well as the peristent segments was observed. This led the authors to postulate restored vasomotion 2 years after implantation of the device. One of the reasons the scaffolded segments did not show restored vasomotion in our trial may be the earlier time point (average 15 months) of our assessment. It should be pointed out that initial marketing campaigns suggested a complete bioabsorption of the device within 2 years after implantation. It is now known from several studies that bioabsorption takes longer than 2 years, and some research groups have pointed out potential safety issues associated with the lack of bioabsorption or the absorption process itself. ${ }^{631}$ Nevertheless, vascular healing as assessed by OCT was excellent for the BVS and in line with previous analyses by Gomez-Lara $e t$ $a l$ and Serruys et al, with reported uncovered ABSORB struts rates at 1 year of $4.5 \%$ and $3.3 \%$, respectively. ${ }^{73233}$

A normalised light-intensity-based method for estimating BVS bioresorption was developed by Nakatani $e t$ $a l$ in a swine model. ${ }^{34}$ They found that normalised light intensity on OCT (which is defined as the signal densitometry on OCT of a polymeric strut core normalised by the vicinal neointima) correlates with the integration of poly-L-lactic acid scaffolds into the arterial wall. A surge in normalised light intensity is a surrogate for strut integration into the vessel wall. They applied their method on OCT pullbacks from the ABSORB Cohort B at 36 months and found astonishingly low-light intensity indexes, suggesting slower strut integration in humans than pigs.

In our analysis, all BVS struts were still visible on OCT as clearly demarked black boxes at 15 months. This correlates with the early stage of bioresorption/strut integration according to the Nakatani et almodel. The devices implanted in the simple lesions of ABSORB Cohort B showed very little advanced bioresorption at 36 months, and we would not expect to find bioresorption/strut integration in the BVS implanted in our patients at an earlier point in time. In the aftermath of ABSORB II, lumen enlargement after intracoronary nitroglycerin administration seems to be an unreliable marker for PLLA-scaffold resorption given that metallic stents with persistent polymer show unexpectedly similar lumen enlargements after intracoronary nitroglycerin. This raises the question of the optimal time point for scaffold/stent vasomotion testing. We postulate that if a difference/BVS superiority in vasomotion were ever to be demonstrated the comparison should be performed only once the scaffold is fully resorbed. Unfortunately, this time point is unknown and most likely varies depending on patient and/or implantation techniques. Nevertheless, longer-term follow-up $(>5$ years) from various BVS trials using intravascular imaging with the aforementioned normalised light intensity index may provide answers.

\section{LIMITATIONS}

The present trial was not randomised and may thus suffer from selection bias. The sample size was small. OCT imaging was not available at baseline, which may represent another limitation. Furthermore, uncertainty with regard to statistical power may limit the validity of the results as they may have been affected by a type II error or may be the result of random variation.

\section{CONCLUSION}

Unlike earlier generation DES, everolimus-eluting bioabsorbable vascular scaffolds and thin strut BP-EES display a reassuring vasomotion profile, suggesting minimal ED 15 months after implantation. Vascular healing 15 months after implantation of these devices is excellent. 
Contributors DAA provided substantial contributions to the analysis of data for the work and was involved in drafting the manuscript and then revised it critically for important intellectual content and gave his final approval of the version to be published and agrees to be accountable for all aspects of the work in ensuring that questions related to the accuracy or integrity of any part of the work are appropriately investigated and resolved. SS provided substantial contributions to the acquisition and analysis of data for the work and was involved in drafting the manuscript and then revised it critically for important intellectual content and gave her final approval of the version to be published and agrees to be accountable for all aspects of the work in ensuring that questions related to the accuracy or integrity of any part of the work are appropriately investigated and resolved. ZK provided substantial contributions to the acquisition and analysis of data for the work and revised the manuscript critically for important intellectual content and gave her final approval of the version to be published and agrees to be accountable for all aspects of thework in ensuring that questions related to the accuracy or integrity of any part of the work are appropriately investigated and resolved. J-CS, GB and J-JG provided substantial contributions to conception of the work and the acquisition and interpretation of data for the work and revised the manuscript critically for important intellectual content and gave his final approval of the version to be published and agrees to be accountable for all aspects of the work in ensuring that questions related to the accuracy or integrity of any part of the work are appropriately investigated and resolved. MT provided substantial contributions to conception and design of the work and the acquisition and interpretation of data for the work and revised the manuscript critically for important intellectual content and gave his final approval of the version to be published and agrees to be accountable for all aspects of the work in ensuring that questions related to the accuracy or integrity of any part of the work are appropriately investigated and resolved. SC provided substantial contributions to conception and design of the work and the acquisition, analysis and interpretation of data for the work and revised the manuscript critically for important intellectual content and gave his final approval of the version to be published and agrees to be accountable for all aspects of the work in ensuring that questions related to the accuracy or integrity of any part of the work are appropriately investigated and resolved. SP provided substantial contributions to conception and design of the work and the acquisition, analysis and interpretation of data for the work and was involved in drafting the manuscript and then revised it critically for important intellectual content and gave his final approval of the version to be published and agrees to be accountable for all aspects of the work in ensuring that questions related to the accuracy or integrity of any part of the work are appropriately investigated and resolved.

Funding This trial was an investigator-initiated study supported by an unrestricted grant from the Fonds Scientifique Cardiovasculaire (Fribourg, Switzerland). During the study period, the Fonds Scientifique Cardiovasculaire received educational and research grants from Abbott Vascular and a dedicated unrestricted grant from Boston Scientific through the independent investigator research programme. SC received support from the Swiss National Science Foundation (CR32I3_150271/1).

Competing interests SC has received speaker fees/honoraria from Abbott Vascular, Biosensors International, and Boston Scientific.

Patient consent Detail has been removed from this case description/these case descriptions to ensure anonymity. The editors and reviewers have seen the detailed information available and are satisfied that the information backs up the case the authors are making.

Ethics approval The study complied with the Declaration of Helsinki and was approved by the local ethics committee at University and Hospital Fribourg, Switzerland.

Provenance and peer review Not commissioned; externally peer reviewed.

Open Access This is an Open Access article distributed in accordance with the Creative Commons Attribution Non Commercial (CC BY-NC 4.0) license, which permits others to distribute, remix, adapt, build upon this work non-commercially, and license their derivative works on different terms, provided the original work is properly cited and the use is non-commercial. See: http://creativecommons.org/ licenses/by-nc/4.0/

(c) Article author(s) (or their employer(s) unless otherwise stated in the text of the article) 2018. All rights reserved. No commercial use is permitted unless otherwise expressly granted.

\section{REFERENCES}

1. Joner M, Finn AV, Farb A, et al. Pathology of drug-eluting stents in humans: delayed healing and late thrombotic risk. J Am Coll Cardiol 2006;48:193-202.

2. Finn $\mathrm{AV}$, Joner $\mathrm{M}, \mathrm{Nakazawa} \mathrm{G}$, et al. Pathological correlates of late drug-eluting stent thrombosis: strut coverage as a marker of endothelialization. Circulation 2007;115:2435-41.

3. Cook S, Eshtehardi P, Kalesan B, et al. Impact of incomplete stent apposition on long-term clinical outcome after drug-eluting stent implantation. Eur Heart J 2012;33:1334-43.

4. Togni M, Windecker S, Cocchia R, et al. Sirolimus-eluting stents associated with paradoxic coronary vasoconstriction. J Am Coll Cardiol 2005;46:231-6.

5. Togni M, Räber L, Cocchia R, et al. Local vascular dysfunction after coronary paclitaxel-eluting stent implantation. Int $\mathrm{J}$ Cardiol 2007:120:212-20.

6. Cuculi F, Puricel S, Jamshidi P, et al. Optical coherence tomography findings in bioresorbable vascular scaffolds thrombosis. Circ Cardiovasc Interv 2015;8:e002518.

7. Serruys PW, Chevalier B, Sotomi Y, et al. Comparison of an everolimus-eluting bioresorbable scaffold with an everolimus-eluting metallic stent for the treatment of coronary artery stenosis (ABSORB II): a 3 year, randomised, controlled, single-blind, multicentre clinical trial. Lancet 2016;388:2479-91.

8. Nakatani S, Sotomi Y, Ishibashi Y, et al. Comparative analysis method of permanent metallic stents (XIENCE) and bioresorbable poly-L-lactic (PLLA) scaffolds (Absorb) on optical coherence tomography at baseline and follow-up. Eurolntervention 2016;12:1498-509.

9. Kallinikou Z, Arroyo D, Togni M, et al. Vascular response to everolimus- and biolimus-eluting coronary stents versus everolimuseluting bioresorbable scaffolds--an optical coherence tomography substudy of the EVERBIO II trial. Swiss Med Wkly 2016;146:14274.

10. Caramori PR, Lima VC, Seidelin PH, et al. Long-term endothelial dysfunction after coronary artery stenting. J Am Coll Cardiol 1999;34:1675-9.

11. Gordon JB, Ganz P, Nabel EG, et al. Atherosclerosis influences the vasomotor response of epicardial coronary arteries to exercise. $J$ Clin Invest 1989;83:1946-52.

12. Hofma SH, van der Giessen WJ, van Dalen BM, et al. Indication of long-term endothelial dysfunction after sirolimus-eluting stent implantation. Eur Heart J 2006;27:166-70.

13. Kim JW, Suh SY, Choi CU, et al. Six-month comparison of coronary endothelial dysfunction associated with sirolimus-eluting stent versus Paclitaxel-eluting stent. JACC Cardiovasc Interv 2008;1:65-71.

14. Fuke S, Maekawa K, Kawamoto K, et al. Impaired endothelial vasomotor function after sirolimus-eluting stent implantation. Circ $J$ 2007;71:220-5

15. Roura G, Homs S, Ferreiro JL, et al. Preserved endothelial vasomotor function after everolimus-eluting stent implantation. Eurolntervention 2015;11:643-9

16. Hamilos M, Ribichini F, Ostojic MC, et al. Coronary vasomotion one year after drug-eluting stent implantation: comparison of everolimuseluting and paclitaxel-eluting coronary stents. J Cardiovasc Trans/ Res 2014;7:406-12.

17. Mitsutake Y, Ueno T, Yokoyama S, et al. Coronary endothelial dysfunction distal to stent of first-generation drug-eluting stents. JACC Cardiovasc Interv 2012;5:966-73.

18. Fujii K, Kawasaki D, Oka K, et al. Endothelium-dependent coronary vasomotor response and neointimal coverage of zotarolimus-eluting stents 3 months after implantation. Heart 2011;97:977-82.

19. Won H, Kim JS, Shin DH, et al. Relationship between endothelial vasomotor function and strut coverage after implantation of drugeluting stent assessed by optical coherence tomography. Int $J$ Cardiovasc Imaging 2014;30:263-70.

20. Kereiakes DJ, Meredith IT, Windecker S, et al. Efficacy and safety of a novel bioabsorbable polymer-coated, everolimus-eluting coronary stent: the EVOLVE II Randomized Trial. Circ Cardiovasc Interv 2015;8:e002372.

21. James SK. Stent thrombosis update: causes, predictors, implications, and treatment. San Francisco, CA, USA: Transcatheter Cardiovascular Therapeutics, 2015.

22. de la Torre Hernández JM, Tejedor P, Camarero TG, et al. Early healing assessment with optical coherence tomography of everolimus-eluting stents with bioabsorbable polymer (synergy ${ }^{\mathrm{TM}}$ ) at 3 and 6 months after implantation. Catheter Cardiovasc Interv 2016;88:E67-73.

23. Tellez A, Seifert PS, Donskoy E, et al. Experimental evaluation of efficacy and healing response of everolimus-eluting stents in the familial hypercholesterolemic swine model: a comparative study of 
bioabsorbable versus durable polymer stent platforms. Coron Artery Dis 2014;25:198-207.

24. Puricel S, Arroyo D, Corpataux N, et al. Comparison of everolimus- and biolimus-eluting coronary stents with everolimuseluting bioresorbable vascular scaffolds. J Am Coll Cardiol 2015;65:791-801.

25. Ellis SG, Kereiakes DJ, Metzger DC, et al. Everolimus-eluting bioresorbable scaffolds for coronary artery disease. N Engl J Med 2015;373:1905-15.

26. Stone GW, Gao R, Kimura T, et al. 1-year outcomes with the absorb bioresorbable scaffold in patients with coronary artery disease: a patient-level, pooled meta-analysis. Lancet 2016;387:1277-89.

27. Lipinski MJ, Escarcega RO, Baker NC, et al. Scaffold thrombosis after percutaneous coronary intervention with absorb bioresorbable vascular scaffold: a systematic review and meta-analysis. JACC Cardiovasc Interv 2016;9:12-24.

28. Cassese S, Byrne RA, Ndrepepa G, et al. Everolimus-eluting bioresorbable vascular scaffolds versus everolimus-eluting metallic stents: a meta-analysis of randomised controlled trials. Lancet 2016;387:537-44.

29. Diletti R, Serruys PW, Farooq V, et al. ABSORB II randomized controlled trial: a clinical evaluation to compare the safety, efficacy, and performance of the absorb everolimus-eluting bioresorbable vascular scaffold system against the xience everolimus-eluting coronary stent system in the treatment of subjects with ischemic heart disease caused by de novo native coronary artery lesions: rationale and study design. Am Heart J 2012;164:654-63.

30. Serruys PW, Ormiston JA, Onuma Y, et al. A bioabsorbable everolimus-eluting coronary stent system (ABSORB): 2-year outcomes and results from multiple imaging methods. Lancet 2009;373:897-910.

31. Räber L, Brugaletta S, Yamaji K, et al. Very late scaffold thrombosis: intracoronary imaging and histopathological and spectroscopic findings. J Am Coll Cardiol 2015;66:1901-14.

32. Serruys PW, Onuma Y, Dudek D, et al. Evaluation of the second generation of a bioresorbable everolimus-eluting vascular scaffold for the treatment of de novo coronary artery stenosis: 12-month clinical and imaging outcomes. J Am Coll Cardiol 2011:58:1578-88.

33. Gomez-Lara J, Radu M, Brugaletta S, et al. Serial analysis of the malapposed and uncovered struts of the new generation of everolimus-eluting bioresorbable scaffold with optical coherence tomography. JACC Cardiovasc Interv 2011;4:992-1001.

34. Nakatani $S$, Ishibashi $Y$, Sotomi $Y$, et al. Bioresorption and vessel wall integration of a fully bioresorbable polymeric everolimus-eluting scaffold: optical coherence tomography, intravascular ultrasound, and histological study in a porcine model with 4-year follow-Up. JACC Cardiovasc Interv 2016;9:838-51. 